\title{
Artículo Especial: Obras maestras del arte universal y la medicina: "Muerte en Venecia" de Thomas Mann (1875-1955)
}

\author{
Universal Art Masterpieces and Medicine: Death in Venice by Thomas Mann
}

Carlos Musso*

\begin{abstract}
"El interés por la enfermedad y la muerte sólo es otra expresión del interés por la vida"
\end{abstract}

Thomas Mann

\begin{abstract}
Resumen
En el presente artículo se sintetiza el argumento de la obra de Thomas Mann Muerte en Venecia. En la misma, se describe el derrotero del respetado escritor Gustav von Aschenbach y su experiencia amorosa - transformadora y trágica - durante un viaje a Venecia. El autor del presente artículo describe a continuación diversas metáforas de la muerte presentadas en la obra comentada, así como sus ideas directrices y su relación con la medicina asistencial. Asimismo, se señala la obra como una oportunidad para comprender lo diverso, inescrutable y respetable de la autodeterminación humana.
\end{abstract}

\section{Abstract}

In the present article the plot of Thomas Man's play Death in Venice is synthesized. In that play, the story of the respected writer Gustav von Aschenbach during a trip to Venice that transformed him, with ingredients of love and tragedy is described. The author of the present essay describes also different metaphors about death present in the play, and also its main ideas and their relationship with medicine. Adiitionally, this play is an excellent opportunity to understand the diversity, mysteriousness and respectability of human self-determination.

Palabras clave: muerte, bioética, principio de autonomía. Key words: death, bioethics, authonomy principle.

Musso C. Obras maestras del arte universal y la medicina: Muerte en Venecia de Thomas Mann. Evid. actual. páct. ambul. 11(1); 18-19 .Ene-Feb 2008.

\section{Argumento}

Gustav von Aschenbach era un respetado escritor que había forjado su obra a fuerza de arduo trabajo y autodisciplina, pues la clave de su pensamiento era que lo grande existe como un "a pesar de", y adquiere forma pese a la aflicción, los tormentos, la miseria, el abandono, la debilidad física, el vicio, la pasión y mil impedimentos más.

Sin embargo, a pesar de su éxito artístico, él no estaba íntimamente contento con su obra, a la cual consideraba carente de verdadera pasión.

Una tarde, esperando el tranvía en la estación lindante al cementerio, vio salir por la entrada principal del mismo a una persona de aspecto fantasmagórico. Tras esta impresión sintió un deseo irrefrenable de viajar y se embarcó rumbo a Venecia. A bordo de su embarcación viajó con él una comitiva de jóvenes. Sin embargo descubrió a posteriori, con desagrado, que uno de ellos era en realidad un anciano decrépito que, a juzgar por su atuendo y maquillaje, pretendía sin lograrlo ser un joven más. Una vez en Venecia, fue conducido por un siniestro y misterioso gondolero hasta San Marcos. Luego se alojó en un hotel, dónde también lo hizo un grupo familiar integrado por una señora madre, una institutriz, tres señoritas de aspecto monjil y un adolescente llamado Tadzio, de una hermosura enfermiza. Aschenbach se enamoró perdidamente de él, llegando incluso dicha atracción a ser mutua. Impulsado por el amor, el escritor comenzó a asistir diariamente al peluquero del hotel, quien a base de tinturas y maquillaje, intentaba darle un aspecto juvenil. Irónicamente, se comportaba Aschenbach en ese momento, como el anciano de la embarcación por quien semanas antes había experimentado tanto rechazo.

Mientras tanto, era un secreto a voces que Venecia vivía una terrible epidemia de cólera, y pese a que Aschenbach se había enterado de ello, decidió "irracionalmente" permanecer en la ciudad, aun a riesgo de morir, ya que el partir hubiese implicado no sólo no ver nunca más a Tadzio, sino además dejar de experimentar esa inusitada liberación de su sensibilidad, que de abandonar Venecia se esfumaría, volviendo a ser el encorsetado artista de siempre.

Aschenbach permaneció en Venecia, tras lo cual cayó victima de la epidemia y murió, pero tal vez el haber sido, de alguna forma, autor de su propia muerte estando en plena erupción de su sensibilidad, haya sido su obra artística más lograda, una obra que lo situó por encima de su muerte.

\section{Algunas consideraciones preliminares}

El protagonista de esta obra, como lo reconociera Thomas Mann, fue inspirado en el genial músico Gustav Mahler (18601911) cuyo talento, autoexigencia y disciplina lo llevaron a ser uno de los más grandes compositores del siglo XX. Por otro lado, a lo largo de la obra se presentan diversas metáforas de la muerte:

- El escenario elegido para la historia fue la ciudad de Venecia, que por su belleza letal es un símbolo de muerte. Una ciudad que tras un pasado de gloria se va hundiendo lenta e inexorablemente en el mar Adriático. En muchas mitologías el infra-mundo está separado del mundo de los mortales por un mar o un río legendarios, son las aguas-madres que funcionan como una suerte de útero (líquido amniótico) desde dónde la muerte, en el plano de los vivos trasmuta en un nacimiento en el plano de los espíritus. Venecia, ciudad acuática por excelencia en el imaginario occidental, constituye un escenario perfecto para el desarrollo de esta historia.

- El apellido del protagonista principal "Aschenbach" significa literalmente en alemán: arroyo de cenizas, idea que evoca un flujo de fuego (vitalidad) extinto, muerto.

- A lo largo del relato se deja entrever que la muerte, bajo distintas figuras, va conduciendo al protagonista hasta su desenlace fatal:

El deseo de viajar le surgió cuando vio a un ser de aspecto cadavérico saliendo del cementerio:

"...sus labios parecían excesivamente cortos: se habían replegado por completo detrás de los dientes que, blancos y largos, sobresalían en el centro, descubiertos hasta las encías..."

Luego se topó en el barco con un viejo decrépito:

... se percató, no sin terror, de que se trataba de un falso joven. Era un hombre viejo, no cabía la menor duda. Hondas arrugas le cercaban ojos y boca. El opaco carmín de sus mejillas era maquillaje; el cabello castaño era una peluca..." 
Posteriormente fue transportado por un personaje siniestro y misterioso en una embarcación de aspecto fúnebre (imagen evocadora de Caronte conduciendo a un difunto por la laguna Estigia):

"...una góndola veneciana negra, como sólo pueden serlo, entre todas las cosas, los ataúdes,...evoca aún más la muerte misma, el féretro y la lobreguez del funeral, así como el silencioso viaje final..."

Una vez en Venecia, la gran metáfora de la muerte podría ser el mismísimo Tadzio. Destaquemos por empezar que la muerte en alemán es de género masculino (der Tod) y que justamente el nombre del muchacho (Tadzio) podría ser un anagrama de la palabra muerte: Tadzio / Tod. Además recordemos el aspecto pálido y enfermizo del adolescente:

"...había observado, sin embargo, que los dientes de Tadzio no eran del todo impecables: un tanto irregulares y pálidos, sin el esmalte que les confiere la salud, tenían esa peculiar y frágil transparencia que a veces se observa en la clorosis (anemia). "Se lo ve muy delicado y enfermizo, pensó Aschenbach, es probable que no llegue a viejo..."

Por otra parte, Tadzio va acompañado de tres hermanas que podrían ser una alegoría de Las Parcas. Finalmente, antes de morir Aschenbach observa como desde la playa Tadzio le señala su destino final:

"... tuvo la impresión de que el pálido y adorable Tadzio le sonreía a lo lejos, de que le hacía señas; como si, separando su mano de la cadera, le señalase un camino y lo empezara a guiar, etéreo, hacia una inmensidad cargada de promesas. $Y$, como tantas otras veces, se dispuso a seguirlo...aquel mismo día, un mundo respetuosamente conmovido recibió la noticia de su muerte..."

\section{Ideas directrices}

Desde el punto de vista de la medicina asistencial Muerte en Venecia es un canto a la autodeterminación humana.

Clásicamente se han descripto como principios de la bioética a la autonomía, la beneficencia, la no maleficencia y la justicia. Solamente, teniendo en cuenta estos principios bioéticos, es que puede lograrse una perspectiva global de la problemática del enfermo durante nuestra labor sanitaria, ya que el primero de estos principios brinda la perspectiva del paciente (la preferencia del enfermo) los dos siguientes la de la medicina (ayu- dar sin dañar) y el último de ellos la de la comunidad (distribución equitativa del recurso sanitario). Incluso, es justamente el principio de autonomía, con su respeto a la elección hecha por el paciente lúcido y debidamente informado, el antídoto más efectivo contra el paternalismo médico.

Aschenbach decide correr el riesgo de morir, y de hecho muere, antes que exponerse al riesgo de perder tanto a la persona de la cual se ha enamorado (perspectiva del enamorado) como el estado de inspiración al cual había tanto deseado arribar en toda su vida (perspectiva del artista):

"...los ciudadanos extranjeros no sabían ni sospechaban de la existencia de la epidemia, no estaban alarmados. La consigna era callar!, pensó Aschenbach irritado...Pero al mismo tiempo un sentimiento de satisfacción embargó su alma al imaginar la aventura en que iba a verse envuelto su entorno inmediato. Pues la pasión, al igual que el crimen, se aviene mal con el orden establecido y el bienestar de la vida cotidiana, y cualquier dislocación del sistema burgués, cualquier confusión o calamidad que amenace al mundo le resultarán forzosamente gratas"

"...Aschenbach sentía, pues un oscuro regocijo, por ese perverso secreto de la ciudad que se fundía con el suyo propio... pues nada lo angustiaba más que la posibilidad de que Tadzio se marchara..."

Cabe preguntarnos, ¿podría alguien que no fuese artista, ni estuviese atravesando una situación emocional similar a la de este escritor comprender cabalmente su decisión? Seguramente no, e incluso la rotularía de insensata. Pero resulta que quien está en el ojo del problema es Gustav Aschenbach, de modo que nadie mejor que él para tomar una decisión que le atañe tan entrañablemente, por más irracional que ésta le pueda llegar a parecer al resto del mundo.

Llegamos entonces a un concepto fundamental: las perspectivas (principios) de la bioética no son sólo cuatro, sino en realidad infinitas, si tenemos en cuenta la multiplicidad de combinaciones que se abren ante la diversidad de tipos de pacientes y médicos, así como de sus respectivas circunstancias. Sólo la adecuada comunicación entre las partes en juego, así como el consiguiente respeto a aquello decidido por el enfermo permiten lograr un acto médico genuino.

Otras ideas, que según diversos críticos, atraviesan esta obra son la de la importancia de la búsqueda de lo bello por parte de un artista; así como la disidencia entre sus aspiraciones estéticas y su condición burguesa.

Podemos concluir que la lectura de la obra Muerte en Venecia de Thomas Mann representa una excelente oportunidad para comprender lo diverso, lo inescrutable y lo respetable de la autodeterminación humana.

\section{Referencias}

Amalfi F. El taller de los escritores. Barcelona. Editorial Océano. 2005

Arcella I. Los hombres: Luchino Visconti. Buenos Aires. Centro Editor de América Latina. 1986

Bloom H. Genios. Bogotá. Grupo Editorial Norma. 2005

Mahler G. Quinta sinfonía en do sostenido menor. 1901-1902 (sinfonía)

Mann T. Muerte en Venecia. Barcelona. Alfred Nobel.1994

Morin E. El hombre y la muerte. Barcelona. Kairos.1974

Musso C, Enz P. Sísifo y la roca de sus principios. Revista del Hospital Italiano (en prensa).

Velasco J. Mahler: Quinta sinfonía. Buenos Aires. Pressur Corporation. 2005

Visconti L. Muerte en Venecia. 1971 (film) 